Pesq. Vet. Bras. 36(3):197-203, março 2016 DOI: $10.1590 / \mathrm{S} 0100-736 \mathrm{X} 2016000300008$

\title{
Comparação entre a citopatologia por biopsia com agulha fina e a histopatologia no diagnóstico das neoplasias cutâneas e subcutâneas de cães ${ }^{1}$
}

\author{
Paulo H. Braz ${ }^{2 *}$, Karine B. Brum ${ }^{3}$, Alda I. Souza² e Maria A.G.S. Abdo ${ }^{3}$
}

\begin{abstract}
Braz P.H., Brum K.B., Souza A.I. \& Abdo M.A.G.S. 2016. [Comparison between cytopathology with fine needle biopsy and histopathology for the diagnosis of cutaneous and subcutaneous neoplasm of dogs.] Comparação entre a citopatologia por biopsia com agulha fina e a histopatologia no diagnóstico das neoplasias cutâneas de cães. Pesquisa Veterinária Brasileira 36(3):197-203. Faculdade de Medicina Veterinária e Zootecnia, Laboratório de Patologia Clínica Veterinária. Universidade Federal de Mato Grosso do Sul, Campo Grande, MS 79074-460, Brazil. E-mail: pauloh.braz@hotmail.com

The cutaneous cancers are among the most frequently diagnosed in veterinary medicine before it is sought that the diagnosis of these tumors are fast and effective. In veterinary medicine the use of cytology as a method for diagnosis has increased. Therefore is necessary that studies demonstrate the technical efficiency so that it can be used as only tool. This study aimed to compare the diagnosis made by cytological and histological techniques. Skin and subcutaneous tumors of dogs and their neoplastic type are more easily diagnosed by cytology and are the most prevalent tumors in this animal spécies, attended by two veterinary hospitals in Campo Grande/MS from March 2012 to December 2013. Tumor cell samples were collected by fine needle aspiration and surgical punch of 91 dogs. The cytological results showed an efficacy of $69.69 \%$ in relation to histopathology. For differentiating between neoplastic and non-neoplastic growth, the efficiency increases to $91.91 \%$. In order to differentiate benign from malignant tumors, it was possible to find an agreement in the order of $68.13 \%$. The most prevalent tumors were mastocytoma, followed by lipoma, fibrosarcoma and basal cell tumor.
\end{abstract}

INDEX TERMS: Cancer, malignancy, tumor cells.

RESUMO.- Os neoplasmas cutâneos estão entre os mais diagnosticados em medicina veterinária, diante disso busca-se que o diagnóstico desses tumores seja rápido e eficaz. Em medicina veterinária o uso da citopatologia como método para diagnóstico tornou-se crescente. Diante disso, é necessário que estudos comprovem a eficiência da técnica para que a mesma possa ser usada de maneira isolada. Este trabalho teve como objetivo comparar o diagnóstico obtido pelas técnicas citopatológica e histopatológica de tumores cutâneos e subcutâneos de cães, determinar qual o tipo neoplásico mais facilmente diagnosticado pela citopatologia

\footnotetext{
${ }^{1}$ Recebido em 8 de julho de 2015.

Aceito em 8 de janeiro de 2016.

${ }^{2}$ Laboratório de Patologia Clínica Veterinária, Faculdade de Medicina Veterinária e Zootecnia, Universidade Federal de Mato Grosso do Sul (UFMS), Campo Grande, MS 79074-460, Brasil. *Autor para correspondência: pauloh.braz@hotmail.com

${ }^{3}$ Laboratório de Patologia, Centro de Ciências Biológicas e da Saúde, UFMS, Campo Grande, MS 79074-460, Brasil.
}

e a neoplasia mais prevalente nesses animais, atendidos em dois hospitais veterinários de Campo Grande/MS, no período de março de 2012 a dezembro de 2013. Foram coletadas amostras celulares de tumores de 91 cães, através de punção aspirativa por agulha fina e punch cirúrgico Os resultados citopatológicos demonstraram uma eficácia de 69,69\%, em relação à histopatologia. Para a diferenciação entre tumores neoplásicos e não neoplásicos, a eficiência aumenta, com resultados iguais em 91,91\%. Para diferenciar tumores benignos de malignos, foi possível chegar a uma concordância na ordem de $68,13 \%$. Os tumores mais prevalentes foram o mastocitoma, seguido do lipoma, fibrossarcoma e tumor de célula basal.

TERMOS DE INDEXAÇÃO: Câncer, malignidade, células tumorais.

\section{INTRODUÇÃO}

A pele, considerada o maior órgão do corpo, está constantemente exposta a uma variedade de agentes químicos, físicos e ambientais, que propiciam às proliferações neoplá- 
sicas. Os neoplasmas cutâneos e subcutâneos são descritos como os mais comuns em cães, representando cerca de um terço de todos os tumores encontrados nesta espécie (Rothwell et al. 1987, Guzman 2003, Bellei et al. 2006).

As formas mais comuns de diagnóstico de tumores de pele são as técnicas citopatológica e histopatológica. A citopatologia tem sido amplamente difundida e começou a ser mais utilizada devido a sua praticidade (Guedes et al. 2000, Lavalle 2003). Nos neoplamas cutâneos e subcutâneos é possível realizar uma avaliação rápida, pouco invasiva e de baixo custo quando comparada a histopatologia (Rocha 2008, Nigam et al. 2013). Diferentemente da citopatologia, o exame histopatológico permite a avaliação da arquitetura tecidual, que possibilita verificar se há perda da organização tecidual e a sua relação com os tecidos adjacentes, o que possibilita estabelecer se as células tumorais são invasivas ou não (Motosugi et al. 2001).

Ao considerar todos esses pontos e devido aos poucos relatos de incidência e comparação entre as técnicas citopatológica e histopatológica no Brasil (Guedes et al. 2000, Magalhães et al. 2001) e a ausência de trabalhos na região de Mato Grosso do Sul, objetivou-se comparar o diagnóstico obtido pelas técnicas citopatológica e histopatológica de tumores cutâneos e subcutâneos de cães, determinar qual o tipo neoplásico mais facilmente diagnosticado pela citopatologia e o neoplasma mais prevalente nesses animais, atendidos em dois hospitais veterinários de Campo Grande/MS.

\section{MATERIAL E MÉTODOS}

Neste estudo foram utilizados 91 cães de diversas raças e idades, atendidos no ambulatório da Faculdade de Medicina Veterinária e Zootecnia da Universidade Federal de Mato Grosso do Sul (Famez/UFMS) e no Hospital Veterinário da Universidade Anhanguera-Uniderp, no período de março de 2012 a dezembro de 2013.

Todos os animais passaram por anamnese e exame físico. Aqueles que apresentaram algum tumor cutâneo ou subcutâneo foram incluídos no projeto. Considerou-se tumor, qualquer aumento de volume cutâneo ou subcutâneo. Foram coletadas duas amostras biológicas por tumor. Um para análise citopatológica e outra para análise histopatológica.

A técnica executada para colheita de material citopatológico foi aquela descrita por Meinkoth et. al. (2008). Para a realização do procedimento, a área do tumor foi higienizada com álcool 70\%, e realizada a colheita com auxílio de uma agulha $(25 \times 7 \mathrm{~mm})$ e seringa padrão (5ml) acoplada. Foi feita uma punção por nódulo e o material biológico foi distribuído em 3 lâminas de vidro diferentes, e posteriormente corado com corante tipo Panótico.

A biópsia para exame histopatológico ocorreu logo após a colheita do material citopatológico, com o auxílio de um punch ou por procedimento cirúrgico, de acordo com o consentimento e autorização do proprietário. Os fragmentos para a análise histopatológica foram padronizados em tamanho aproximado de $1 \mathrm{~cm}$ $\mathrm{x} 1 \mathrm{~cm}$. 0 fragmento foi conservado em formol tamponado a $10 \%$. Após fixação do material por pelo menos 24 horas, a amostra foi processada rotineiramente, cortada a $5 \mu$ e corada pela técnica de hematoxilina e eosina (H\&E).

A avaliação das lâminas citopatológicas e histopatológicas foram feitas de forma independente por avaliadores diferentes. Para a análise citopatológica, dois avaliadores fizeram simultaneamente a leitura da lâmina e para a análise histopatológica, outros dois avaliadores fizeram os diagnósticos. Os resultados das duas técnicas somente comparados ao final de todas as análises, a fim de não influenciar nas leituras das lâminas.

Os diagnósticos citopatológicos foram comparados com os apresentados por Cowell et al. (2008) e Raskin \& Meyer (2011). 0 diagnóstico histopatológico foi comparado com os apresentados por Meuten (2002).

Os cães que apresentaram mais de um tumor foram incluídos no levantamento mais de uma vez, dentro de cada entidade específica. Dessa forma, há um maior número de tumores do que de cães. Tumores primários mamários, diagnosticados pela histopatologia, foram desconsiderados do estudo.

\section{RESULTADOS E DISCUSSÃO}

A avaliação das amostras biológicas dos 91 cães resultou em um total de 99 tumores e na identificação de 31 neoplasmas diferentes, diagnosticadas a partir do exame histopatológico. Dentre todos os tumores avaliados, foi possível emitir um diagnóstico citopatológico idêntico ao diagnóstico histopatológico em 69 casos (69,69\%). A comparação dos resultados citopatológicos e histopatológicos e a localização anatômica dos tumores estão descritos no Quadro 1.

Dos tumores estudados, seis foram considerados processos não neoplásicos pela técnica citopatológica, sendo um deles conclusivo pela histopatologia como sendo Tumor de Meibomio. Dois casos foram considerados insuficientes para análise devido à hemodiluição, porém, em ambos os casos a histopatologia revelou o diagnóstico de adenoma sebáceo. Quadro 2 apresenta a distribuição e quantidade dos diferentes tumores cutâneos e subcutâneos encontrados.

Ao classificar os tumores encontrados na histopatologia, $34(34,34 \%)$ eram de células redondas, 31 (31,31\%) epiteliais, $28(28,28 \%)$ mesenquimais, $5(5,05 \%)$ processos inflamatórios e $1(1,01 \%)$ tumor misto, também chamado de carcinossarcoma, proveniente provavelmente de metástase, uma vez que é uma neoplasia primária de glândula mamária e estava localizado distante do seu local de origem. Ghisleni et al. (2006), encontraram dentre os 175 tumores, 69 (39\%) de origem mesenquimal, 56 (32\%) de células redondas e 51 (29\%) epiteliais. Mesmo que os tumores tenham sido escolhidos ao acaso, nota-se que a frequência na classificação dos mesmos mantém-se semelhante entre os trabalhos, inferindo uma linearidade na divisão destes grupos.

De acordo com a classificação utilizada por Meirelles et al. (2010), quanto ao sítio de origem da neoplasia, 50,5\% (514/1.017) dos casos eram de origem mesenquimal, $45,1 \%$ (459/1.017) epitelial e 3,9\% (40/1.017) melanocítica. Já Magalhães et. al. (2001), entre as 150 neoplasias estudadas, encontraram valores de $74(49,3 \%)$ de origem mesenquimal, $26(17,3 \%)$ epiteliais, $7(4,7 \%)$ de origem neuroectodérmica. Caso considerássemos a mesma classificação teríamos valores na histopatologia de 59,59\% de neoplasias de origem mesenquimal, $31,31 \%$ epitelial e 3,03\% neuroectodérmica. Ao comparar os resultados é possível observar que as neoplasias mesenquimais são as mais frequentes, seguidas pelas de origem epitelial. Mesmo que em regiões climáticas diferentes, os tumores de origem neuroectodérmica são encontrados em pequena quantidade (Chiarelli-Neto et al. 2014, Premi et al. 2015). 
Quadro 1. Resultados dos exame e localização dos tumores obtidos pelas técnicas citopatológica e histopatológica em tumores cutâneos e subcutâneos de cães atendidos nos hospitais veterinários das universidades UFMS e AnhangueraUniderp no período de março de 2012 a dezembro de 2013

\begin{tabular}{ccc}
\hline Diagnóstico & Diagnóstico & Local Anatômico - \\
citopatológico & histopatológico & Região ossea
\end{tabular}

Fibrossarcoma Fibrossarcoma Cauda porção ventral

Fibrossarcoma Fibrossarcoma Tórax porção ventral

Neoplasia de celulas re- Histiocitoma fibroso Rádio porção medial

dondas indiferenciado maligno

Sarcoma indiferenciado Carcinoma

Carcinoma de células

escamosas

Tumor misto

Mastocitoma

Mixossarcoma

Hemangiossarcoma

Tricoepitelioma

Epitelioma sebáceo

Carcinoma de células escamosas

Histiocitoma

Hemangioma

Carcinoma de células

basais

Mastocitoma

Fibrossarcoma

Hemangiossarcoma

Hemangiossarcoma

Adenocarcinoma

sebáceo

Hemodiluido

Plasmocitoma

Carcinoma de células

escamosas

Mastocitoma

Adenocarcinoma

sebáceo

Mastocitoma

Melanocitoma

Melanocitoma

Histiocitoma

Epitelioma sebáceo

Hemodiluido

Mastocitoma

Hemodiluido

Hemodiluido

Plasmocitoma

Melanoma

Melanoma

Fibrossarcoma

Plasmocitoma

Tricoepitelioma

Lipossarcoma

Mastocitoma

Plasmocitoma

Lipoma

Melanoma

Plasmocitoma

Adenoma hepatóide perianal indiferenciado

Carcinoma de

Abdômen porção ventral

escamosas

Tumor misto

Mastocitoma

Mixossarcoma

Hemangiossarcoma

Tricoepitelioma

Epitelioma sebáceo

Tórax porção dorsal

Tíbia porção lateral

Tórax porção lateral

Prepúcio

Falange direita, porção

dorsal

Fêmur direito porção

dorsal

Carcinoma de células Abdomên porção ventral escamosas

Histiocitoma

Linfangioma

Tórax porção ventral

Falange direita porção ventral

Carcinoma de células Prepúcio

basais

Mastocitoma

Fibrossarcoma

Tórax porção ventral

Fêmur direito porção

lateral

Hemangiossarcoma Tíbia direira porção

ventral

Hemangiossarcoma Prepúcio

Adenocarcinoma Cauda porção dorsal

sebáceo

Fibrossarcoma Tórax porção ventral

Histiocitose maligna Dígito porção dorsal

Fibrossarcoma Falange direita porção

dorsal

Mastocitoma

Adenocarcinoma

sebáceo

Mastocitoma

Mastocitoma

Melanocitoma

Carcinoma

indiferenciado

Mastocitoma

Mastoctitoma

Mastoctitoma

Adenoma sebáceo

adenoma sebáceo

carcinoma celula

basal

Melanoma

Carcinoma

indiferenciado

Hemangiossarcoma

Plasmocitoma

Tricoepitelioma

Lipossarcoma

Mastocitoma

Lipoma

Lipoma

Melanoma

Plasmocitoma

Adenoma hepatóide

perianal

Falange porção dorsal

Tórax porção dorsal

Fêmur direito porção lateral

Falange porção dorsal

Úmedo porção ventral

Fêmur porção lateral

Fêmur porção medial

Rádio porção lateral

Tórax porção dorsal

Abdômen porção ventral

Dígito porção dorsal

Região perianal
Quadro 1 (Cont.). Resultados dos exame e localização dos tumores obtidos pelas técnicas citopatológica e histopatológica em tumores cutâneos e subcutâneos de cães atendidos nos hospitais veterinários das universidades UFMS e AnhangueraUniderp no período de março de 2012 a dezembro de 2013

\begin{tabular}{ccc}
\hline Diagnóstico & Diagnóstico & Local Anatômico - \\
citopatológico & histopatológico & Região ossea \\
\hline
\end{tabular}

Mastocitoma Plasmocitoma Tórax porção dorsal

Mastocitoma Mastocitoma

Hemangiossarcoma Carcinoma hepatóide

perianal

Condrossarcoma Condrossarcoma

Fibrossarcoma Linfangiossarcoma

Mastocitoma Mastocitoma

Fibrossarcoma Fibrossarcoma

Hemangiossarcoma Linfangiossarcoma

Carcinoma hepatói- Carcinoma hepatóide

de perianal perianal

Mastocitoma Mastocitoma

Adenocarcinoma Adenocarcinoma

sebáceo

sebáceo

Fibrossarcoma Lipossarcoma

Lipoma

Lipoma

Hemangioma

Mastocitoma

Mastocitoma

Hemangioma

Mastocitoma

Mastocitoma

Fibrossarcoma

Carcinoma de células

Abdômen porção ventral

Região perianal

Tórax porção lateral direita

Tórax porção ventral

Tórax porção ventral

Focinho

Bolsa escrotal

Região perianal

Tórax porção dorsal

Dígito porção dorsal

Tórax porção lateral

Tórax porção dorsal

Tórax porção dorsal

Fêmur porsão lateral

Tórax porção ventral

Abdômen porção ventral

Linfoma

Linfoma

Linfoma

Linfoma

Linfoma

Carcinoma indiferenciado Abdômen porção ventral

Carcinoma de células Dígito porção dorsal

basais

Sarcoma indiferenciado

Linfoma

Mastocitoma Hemangioma

Carcinoma hepatói- Carcinoma hepatóide

de perianal perianal

Carcinoma de célu- Carcinoma de célula

las basais basais

Lipoma Lipoma

Lipoma Lipoma

Lipoma Lipoma

Fibrossarcoma Plasmocitoma

Mastocitoma Mastocitoma

Lipoma Carcinoma de células

basais basais

Epitelioma sebáceo Lipoma

Mastocitoma Mastocitoma

Carcinoma de célu- Carcinoma de células

las basais

Epitelioma sebáceo Carcinoma indiferenciado Prepúcio

Reação inflamatória Tumor meiboniano

Mastocitoma Mastocitoma

Reação inflamatória Reação inflamatória

Mastocitoma mastocitoma

Plasmocitoma Plasmocitoma

Lipoma

Lipoma

Mastocitoma

Mastocitoma

Tricoblastoma

Tricoblastoma

Mastocitoma Mastocitoma

Carcinoma hepatói- Carcinoma hepatóide

de perianal perianal

Mastocitoma Mastocitoma

Carcinoma de célu- Carcinoma de células

las escamosas escamosas

Carcinoma de célu- Carcinoma de células

las escamosas

Fibrossarcoma escamosas

Fibrossarcoma

Fibrossarcoma Fibrossarcoma
Tórax porção dorsal Tórax porção lateral Tórax porção lateral Prepúcio

Região perianal

Região pélvica porção ventral

Abdômen porção ventral

Tórax porção lateral

Abdômen porção ventral

Fêmur porção ventral

Tórax porçao dorsal

Fêmur porção medial

Pescoço porção lateral Abdômen porção ventral Fêmur porção lateral

Pálpebra

Tórax porção dorsal

Fêmur porção medial

Abdômen porção ventral

Abdômen porção ventral

Pescoço porção lateral

Abdômen porção ventral

Fêmur porção lateral

Fêmur porção medial

Região perianal

Bolsa escrotal

Pavilhão auricular

Abdômen porção ventral

Abdômen porção lateral

Tórax porção lateral 
Quadro 2. Diferentes neoplasmas diagnosticados pelas técnicas citopatológica e histopatológica em tumores cutâneos e subcutâneos de cães atendidos nos hospitais veterinários das universidades UFMS e Anhanguera-Uniderp no período de março de 2012 a dezembro de 2013

\begin{tabular}{|c|c|c|c|c|c|c|}
\hline $\begin{array}{l}\text { Origem } \\
\text { tecidual }\end{array}$ & $\begin{array}{c}\text { Diagnóstico } \\
\text { citopatológico }\end{array}$ & № & $\%$ & $\begin{array}{c}\text { Diagnóstico } \\
\text { histopatológico }\end{array}$ & № & $\%$ \\
\hline \multirow[t]{11}{*}{ Mesenquimal } & Condrossarcoma & 1 & 1,01 & Condrossarcoma & 1 & 1,01 \\
\hline & Fibrossarcoma & 12 & 12,12 & Fibrossarcoma & 7 & 7,07 \\
\hline & Hemangioma & 2 & 2,02 & Hemangioma & 2 & 2,02 \\
\hline & Hemangiossarcoma & 4 & 4,04 & Hemangiossarcoma & 4 & 4,04 \\
\hline & & & & Linfangioma & 1 & 1,01 \\
\hline & & & & Linfangiossarcoma & 2 & 2,02 \\
\hline & Lipoma & 7 & 7,07 & Lipoma & 8 & 8,08 \\
\hline & Lipossarcoma & 1 & 1,01 & Lipossarcoma & 2 & 2,02 \\
\hline & Mixossarcoma & 1 & 1,01 & Mixossarcoma & 1 & 1,01 \\
\hline & Sarcoma indiferenciado & 1 & 1,01 & & & \\
\hline & Total & 29 & 29,29 & & 28 & 28,28 \\
\hline \multirow[t]{12}{*}{ Epitelial } & Adenocarcinoma sebáceo & 3 & 3,03 & Adenocarcinoma sebáceo & 3 & 3,03 \\
\hline & Adenoma hepatóide & 1 & 1,01 & Adenoma hepatóide & 1 & 1,01 \\
\hline & Adenoma sebáceo & 2 & 2,02 & & & \\
\hline & Carcinoma de célula basal & 3 & 3,03 & Carcinoma de célula basal & 7 & 7,07 \\
\hline & Carcinoma de células escamosas & 5 & 5,05 & Carcinoma de células escamosas & 4 & 4,04 \\
\hline & Carcinoma hepatóide & 3 & 3,03 & Carcinoma hepatóide & 4 & 4,04 \\
\hline & Carcinoma indiferenciado & 5 & 5,05 & & & \\
\hline & Epitelioma sebáceo & 4 & 4,04 & Epitelioma sebáceo & 1 & 1,01 \\
\hline & Tricoblastoma & 1 & 1,01 & Tricoblastoma & 1 & 1,01 \\
\hline & Tricoepitelioma & 2 & 2,04 & Tricoepitelioma & 2 & 2,02 \\
\hline & Tumor de meibon & 1 & 1,01 & & & \\
\hline & Total & 22 & 22,22 & & 31 & 31,31 \\
\hline Células & Células redondas indiferenciado & 1 & 1,01 & Células redondas indiferenciado & 1 & 1,01 \\
\hline \multirow[t]{9}{*}{ redondas } & Histiocitoma & 2 & 2,02 & Histiocitoma & 1 & 1,01 \\
\hline & Histiocitoma fibroso maligno & 1 & 1,01 & & & \\
\hline & Histiocitose maligna & 1 & 1,01 & & & \\
\hline & Linfoma & 5 & 5,05 & Linfoma & 2 & 2,02 \\
\hline & Mastocitoma & 20 & 20,20 & Mastocitoma & 20 & 20,20 \\
\hline & Melanocitoma & 2 & 2,02 & Melanocitoma & 1 & 1,01 \\
\hline & Melanoma & 3 & 3,03 & Melanoma & 2 & 2,02 \\
\hline & Plasmocitoma & 6 & 6,06 & Plasmocitoma & 5 & 5,05 \\
\hline & Total & 39 & 39,39 & & 34 & 34,34 \\
\hline Tumores & Tumor misto & 1 & 1,01 & & 1 & 1,01 \\
\hline mistos & Total & 1 & 1,01 & & 1 & 1,01 \\
\hline \multirow[t]{3}{*}{ Outros } & Tumores não neoplásicos & 6 & 6,06 & Tumores não neoplásicos & 5 & 5,05 \\
\hline & Material hemodiluído & 2 & 2,02 & & & \\
\hline & Total & 8 & 8,08 & & 5 & 5,05 \\
\hline Total & & 99 & 100 & & 99 & 100 \\
\hline
\end{tabular}

Andrade et al. (2012) ao descreverem a origem embrionária dos tumores, os classificaram em células de origem mesenquimal e células de origem epitelial e obtiveram valores de $50,3 \%$ de tumores epiteliais e $49,7 \%$ mesenquimais. Levando-se em conta esta classificação para este estudo, os tumores mesenquimais também seriam dados como os mais frequentes, com um total de 62 casos $(62,62 \%)$, corroborando com estes autores.

Tumores mesenquimais malignos corresponderam a 20 de 29 casos $(68,96 \%)$ na citopatologia e 17 de 28 casos $(60,71 \%)$ na histopatologia. Neste caso, a maior prevalência foi de fibrossarcomas, correspondendo a um total de $41,37 \%$ na citopatologia e $25 \%$ na histopatologia, o que está de acordo com o encontrado por Meirelles et al. (2010) que citaram o fibrossarcoma como o tumor mesenquimal maligno mais recorrente, perdendo apenas para tumores mesenquimais malignos indiferenciados.

Com relação aos tumores mesenquimais benignos, o lipoma foi o tumor de maior prevalência, correspondendo a um total de $24,13 \%$ na citopatologia e $28,57 \%$ na histo- patologia. Fato justificado por Ghisleni et al. (2006) que relacionaram o lipoma como o tumor de tecido mole mais frequentemente encontrado. Dados semelhantes foram encontrados por Souza et al. (2006), Pakhrin et al. (2007) e Meirelles et al. (2010).

Os linfangiomas e linfangiossarcomas não foram diagnosticados na citopatologia. De modo geral, foram confundidos com hemangiomas e hemangiossarcomas, respectivamente. Tanto na histopatologia quanto na citopatologia, os linfangiossarcomas devem ser diferenciados do linfangioma e do hemangiossarcoma por possuirem características semelhantes, nas duas observações (Goldschmidt \& Hendrick 2002).

Tumores epiteliais foram diagnosticados pela citopatologia em 22 casos (22,44\%), sendo 14 malignos e oito benignos. 0 carcinoma de células escamosas foi o tumor epitelial mais encontrado, quando diagnosticado pela citopatologia. Este tumor foi diagnosticado com precisão através da avaliação citológica em cinco de quatro casos, corroborando com o descrito por Nigam et al. (2013). Por 
outro lado, Ménard et al. (1986) definiram os carcinomas escamosos como difíceis de diagnosticar devido a pouca celularidade, presença de restos necróticos e inflamação.

Semelhantemente ao descrito por Magalhães et al. (2001), a morfologia do carcinoma de células basais pode causar dificuldade para interpretação citopatológica, passível de erro com outros carcinomas. Assim, estes tumores ficam em grande parte na dependência da confirmação histopatológica, que permite a visualização da arquitetura tecidual, fato que justifica o baixo número de diagnósticos na citopatologia deste estudo.

Dentre os 150 tumores diagnosticados na histopatologia, Magalhães et al. (2001) obtiveram um total de 2,66\% de tumores de células basais. Já Meirelles et al. (2010), descreveram valores ainda menores, na ordem de $1 \%$ deste tumor. Santos et al. (2013), encontraram valores de 3\% dessa mesma neoplasia. No presente estudo foram encontrados valores superiores, na ordem de 7,07\% dessa neoplasia.

Os neoplasmas cutâneos de células redondas podem ter aparência morfológica similar e o diagnóstico baseado apenas na histopatologia de rotina é frequentemente desafiador, neste caso a citopatologia representa a melhor opção de diagnóstico. Dentre estes tumores estão o linfoma maligno, o histiocitoma, o mastocitoma pouco diferenciado, o plasmocitoma, e o melanoma amelanótico (Goldschmidt \& Hendrick 2002). Uma alternativa para o diagnóstico desse tipo de neoplasias seria a utilização da técnica de imunohistoquímica (Mierau et al. 1985, Ohsie et al. 2008).

Dentre os tumores de células redondas, o mastocitoma foi o tumor mais frequentemente diagnosticado, conforme já descrito por diversos autores (Magalhães et al. 2001, Kiupel et al. 2004, Bellei et al. 2006, Souza et al. 2006, Rodríguez et al. 2009). Resultados diferentes são descritos por Oliveira et al. (2012) em que os principais tumores tegumentares de células redondas descritos são o linfoma cutâneo, seguido por histiocitoma cutâneo.

Quando comparados os diagnósticos citopatológico e histopatológico dos tumores de células redondas, obteve-se semelhança em grande parte deles. A facilidade de esfoliação desse tipo tumoral resultou num elevado número de células presentes no esfregaço (Griffiths, Lumsden \& Valli 1984). Desta forma, em poucos casos houve discordância entre a citopatologia e a histopatologia, fato já observado por outros autores (Magalhães et al. 2001, Rodríguez el al. 2009).

Como já descrito por alguns autores, houve dificuldade no diagnóstico dos casos em que células neoplásicas e leucocitárias faziam parte da mesma lesão, uma vez que células reativas e a displasia causada por processo inflamatório tornaram as células normais semelhantes às células malignas (Montes 1997, Magalhães et al. 2001). Destaca-se, ainda, a dificuldade referida por Magalhães et. al. (2001), em definir o tipo celular neoplásico nas áreas de inflamação, sabendo que uma massa tumoral pode conter locais de reação inflamatória e focos de lesão neoplásica concomitantemente. Nesta vertente, em um caso diagnosticado como plasmocitoma, na citopatologia, recebeu o diagnóstico de lipoma, da histopatologia. Isto porque o tumor possuia grande quantidade de infiltrado plasmocítico.
Os resultados obtidos neste estudo confirmam os registros da literatura, que definem a citopatologia como um método seguro, rápido e eficaz na prática clínica, para diferenciação de lesões neoplásicas e não neoplásicas (Ghisleni et al. 2006, Gupta et al. 2011, Nigam et al. 2013). A concordância entre os exames citopatológico e histopatológico para definir se o tumor era neoplásico ou não foi de 91,91\%. Obteve-se divergência em apenas três tumores, que foram diagnosticados como neoplásico na histopatologia e não neoplásico na citopatologia. Resultados semelhantes foram obtidos por Ghisleni et al. (2006), que encontraram 176 neoplasias diagnosticadas pela citopatologia, confirmadas por meio da histopatologia, e em apenas um caso a citopatologia recebeu diagnóstico falso positivo. No presente estudo, a insuficiência de material para análise devido à hemodiluição ou baixa celularidade, contribuiu para que alguns resultados fossem considerados não neoplásicos pela citopatologia.

Quando avaliada a eficiência da citopatologia em comparação com a histopatologia para diferenciar tumores benignos de malignos, foi possível chegar a uma concordância na ordem de 68,13\%. Semelhantemente, de acordo com os resultados encontrados por Ménard et al. (1986), os tumores malignos foram detectados pela citopatologia na ordem de $71 \%$ e 60 \% em cães e gatos, respectivamente.

Melhores resultados foram encontrados por Guedes et al. (2000), por meio do qual houve discordância entre tumores benignos e malignos em apenas sete casos. Dentre os casos citados, cinco tumores foram considerados mamários. Os tumores mamários são considerados de difícil diagnóstico utilizando-se a citopatologia, dadas às variações morfológicas encontradas (Magalhães et al. 2001). Devido à grande dificuldade de diagnóstico de tumores mamários pela técnica citológica e por pertencerem a outro grupo de classificação tumoral, estes, quando presentes, foram desconsiderados do presente estudo.

Há poucos trabalhos que comparam diagnóstico de tumores de pele obtidos pela citopatologia com os encontrados na histopatologia. Dados fornecidos por Guedes et al. (2000), mostraram a eficácia da citopatologia em 75 (72,22\%) dos 90 casos estudados. Magalhães et al. (2001), chegaram a resultados entre a comparação das técnicas citopatológica e histopatológica na ordem de 85,3\% (128 casos). 0 presente estudo apresentou resultado na ordem de 69,69\% de concorância entre as técnicas citopatológica e histopatológica (Quadro 3) que se atribui a grande diversidade de neoplasmas encontrados.

Quando levado em conta todos os tumores cutâneos e subcutâneos, os mastocitomas foram os neoplasmas mais evidenciados, seguidos pelos fibrossarcomas e lipomas. Um estudo realizado por Bellei et al. (2006) também evidenciaram o mastocitoma como o tumor de pele mais frequente. Resultados diferentes foram encontrados por Rodríguez et al. (2009), que citaram o carcinoma complexo o mais recorrente. Por sua vez, Andrade et al. (2012), quando levado em conta apenas os tumores de pele, encontraram o carcinoma de células escamosas e o hemangiossarcoma, com sendo os mais frequentes, seguidos por mastocitoma e histiocitoma.

Os mastocitomas tiveram concordância entre os diag- 
Quadro 3. Concordância de diagnósticos obtidos pelas técnicas citopatológica e histopatológica em tumores cutâneos e subcutâneos de cães atendidos nos hospitais veterinários das universidades UFMS e Anhanguera-Uniderp no período de março de 2012 a dezembro de 2013

\begin{tabular}{|c|c|c|}
\hline \multirow[t]{2}{*}{ Diagnóstico histopatológico } & \multicolumn{2}{|c|}{ Diagnóstico citopatológico } \\
\hline & $\mathrm{C}$ & $\mathrm{D}$ \\
\hline Adenocarcinoma sebáceo & 3 & 0 \\
\hline Adenoma hepatóide & 1 & 0 \\
\hline Adenoma sebáceo & 0 & 2 \\
\hline Carcinoma de célula basal & 3 & 4 \\
\hline Carcinoma de células escamosas & 4 & 1 \\
\hline Carcinoma hepatóide & 3 & 1 \\
\hline Carcinoma indiferenciado & 0 & 5 \\
\hline Células redondas indiferenciado & 0 & 2 \\
\hline Condrossarcoma & 1 & 0 \\
\hline Epitelioma sebáceo & 1 & 3 \\
\hline Fibrossarcoma & 6 & 6 \\
\hline Hemangioma & 1 & 2 \\
\hline Hemangiossarcoma & 3 & 3 \\
\hline Histiocitoma & 1 & 1 \\
\hline Histiocitoma fibroso maligno & 0 & 1 \\
\hline Histiocitose maligna & 0 & 1 \\
\hline Linfangioma & 0 & 1 \\
\hline Linfangiossarcoma & 0 & 2 \\
\hline Linfoma & 2 & 3 \\
\hline Lipoma & 6 & 3 \\
\hline Lipossarcoma & 1 & 1 \\
\hline Mastocitoma & 18 & 4 \\
\hline Melanocitoma & 1 & 1 \\
\hline Melanoma & 2 & 1 \\
\hline Mixossarcoma & 1 & 0 \\
\hline Plasmocitoma & 3 & 5 \\
\hline Sarcoma indiferenciado & 0 & 1 \\
\hline Tricoblastoma & 1 & 0 \\
\hline Tricoepitelioma & 2 & 0 \\
\hline Tumor de meibon & 0 & 1 \\
\hline Tumor misto & 1 & 0 \\
\hline
\end{tabular}

C = Diagnósticos concordantes, $\mathrm{D}=$ Diagnósticos diferentes.

nósticos em 18 casos. Diferiram-se o diagnóstico em quatro casos, sendo dois tumores diagnosticados como mastocitoma na citopatologia e como plasmocitoma e hemangioma na histopatologia, e outros dois casos em que foram diagnosticados mastocitomas na histopatologia, porém a citopatologia levou ao diagnóstico de epitelioma e melanocitoma. Magalhães et al. (2001), encontraram 22 tumores diagnosticados como mastocitoma, e todos tiveram concordância entre a citopatologia e a histopatoligia. Guedes et al. (2000), dentre os quatro mastocitomas encontrados, também obtiveram $100 \%$ de concordância entre os dois métodos de diagnóstico estudados.

O fibrossarcoma, considerado o segundo tumor mais frequente deste estudo diagnosticado na citopatologia e o quarto mais encontrado na histopatologia, teve concordância entre os diagnósticos citopatológico e histopatológico em sete casos. Foram encontrados cinco casos em que o diagnóstico de fibrossarcoma foi dado somente na citopatologia, diferindo-se na histopatologia, com diagnósticos de carcinoma de células basal, plasmocitoma, lipossarcoma, linfangiossarcoma e hemangiossarcoma. Em um caso o diagnóstico foi de fibrossarcoma na histopatologia e carcinoma de célula basal, na citopatologia. Guedes et al. (2000) obtiveram um total de dois fibrossarcomas diagnosticados, todavia em apenas um dos casos o diagnóstico coincidiu, ao comparar a citopatologia e a histopatologia. Resultados diferentes foram encontrados por Magalhães et al. (2001), uma vez que dentre todas as neoplasias, apenas uma foi considerada fibrossarcoma, tanto na histopatologia quanto na citopatologia. A divergência entre os resultados obtidos pode ser devido a maior incidência deste tipo tumoral encontrado neste trabalho, possibilitando uma maior quantidade de variação celular nos neoplasmas encontrados.

O lipoma foi o terceiro tumor mais encontrado pela citopatologia e o segundo pela histopatologia. Dentre os neoplasmas, seis receberam o mesmo diagnóstico na citopatologia e na histopatologia. Diferiu-se no diagnóstico em um caso, que foi dado como lipoma na citopatologia e tumor de célula basal na histopatologia. Em duas ocasiões os tumores tiveram o diagnóstico de lipoma na histopatologia, todavia a citopatologia sugeriu o diagnóstico de plasmocitoma e epitelioma. Resultados superiores foram encontrados por Magalhães el al. (2001), que apontarsm total concordância dos resultados citopatológicos e histopatológicos dos lipomas.

\section{CONCLUSÕES}

Ao considerar os resultados encontrados, observa-se que a citopatologia oferece a opção de um diagnóstico precoce, cumprindo satisfatoriamente o papel de diferenciar crescimentos neoplásicos de não neoplásicos, além de caracterizar os neoplasmas quanto benignos ou malignos.

Ao fazer a comparação dos resultados obtidos entre a citopatologia e a histopatologia, nota-se boa acertividade. Assim, a citopatologia pode ser considerada um bom método de triagem, todavia o diagnóstico definitivo, em sua grande parte, fica dependente do resultado histopatológico.

Dentre os tipos tumorais, os considerados tumores de células redondas foram os que mais facilmente foram diagnosticados pela citopatologia.

De acordo com os resultados obtidos, foi possível verificar que diante das condições ambientais e regionais, o mastocitoma é o tumor de pele mais prevalente, seguido do lipoma, fibrossarcoma e tumor de célula basal, na região de Campo Grande, Mato Grosso do Sul.

Agradecimentos.- Aos professores da Universidade Federal de Mato Grosso do Sul, Ricardo Antônio Amaral de Lemos e Carlos Eurico dos Santos Fernandes, pelo auxílio de materiais de consumo para que a pesquisa fosse executada.

\section{REFEFÊNCIAS}

Andrade R.L.F.S., Oliveira D.M., Dantas A.F.M., Souza A.P., Nóbrega Neto P.I. \& Riet-Correa F. 2012. Tumores de cães e gatos diagnosticados no semiárido da Paraíba. Pesq. Vet. Bras. 32(10):1037-1040.

Bellei M.H.M., Neves D.S., Gava A., Liz P.P. \& Pilati C. 2006. Prevalência de neoplasias cutâneas diagnosticadas em caninos no estado de Santa Catarina, Brasil, no período entre 1998 e 20021 . Revta Ciênc. Agrovet., Lages, 5(1):73-79.

Chiarelli-Neto O., Ferreira A.S., Martins W.K., Pavani C., Severino D., O-Flores F.F., Maria-Engler S.S., Aliprandini E., Martinez G.R., Di Mascio P., Medeiros M.H.G. \& Baptista M.S. 2014. Melanin Photosensitization and the Effect of Visible Light on Epithelial Cells. Plos One. 9(11):1-9.

Cowell R.L., Tyler R.D., Meinkoth J.H. \& DeNicola D.B. 2008. Diagnostic citology and hematology of the dog and cat. 3rd ed. Mosby Elsevier, Missouri. 
Ghisleni G., Roccabianca P., Ceruti R., Stefanello D., Bertazzolo W. \& Caniatti M. 2006. Correlation between fine-needle aspiration cytology and histopathology in the evaluation of cutaneous and subcutaneous masses from dogs and cats. Vet. Clin. Pathol. 35(1):24-30.

Goldschmidt M.H. \& Hendrick M.J. 2002. Tumors of the skin and soft tissues, p.44-117. In: Meuten D.J. (Ed.), Tumors in Domestic Animals. 4th ed. Iowa State Press, Ames.

Griffiths G.L., Lumsden J.H. \& Valli V.E.O. 1984. Fine needle aspiration cytology and histologic correlation in canine tumors. Vet. Clin. Pathol. 13(1):13-17.

Guedes R.M.C., Zica K.G.B., Coelho-Guedes M.I.M. \& Oliveira S.R. 2000. Acurácia do exame citológico no diagnóstico de processos inflamatórios e proliferativos dos animais domésticos. Arq. Bras. Med. Vet. Zootec. 52(5):437-439.

Gupta N., Kaur J., Srinivasan R., Das A., Mohindra S. \& Rajwanshi A. 2011. Fine needle aspiration cytology in lesions of the nose, nasal cavity and paranasal sinuses. Acta Cytol. 55:135-41.

Guzman E., Langowski J.L. \& Owen-Schaub L. 2003. Mad dogs, Englishmen and apoptosis: the role of cell death in UV-induced skin cancer. Apopt. 4:315-325.

Kiupel M., Webster J.D. \& Kaneene J.B. 2004. The use of Kit and Tryptase expression patterns as prognostic tools for canine cutaneous mast cell tumors. Vet. Pathol. 41(4):371-377.

Lavalle G.E., Araújo R.B., Carneiro R.A. \& Pereira L.C. 2003. Punção aspirativa por agulha fina para diagnóstico de mastocitoma em cães. Arq. Bras. Med. Vet. Zootec. 55(4):500-502.

Magalhães A.M., Ramadinha R.R., Barros C.S.L. \& Peixoto P.V. 2001. Estudo comparativo entre citopatologia e histopatologia no diagnóstico de neoplasias caninas. Pesq. Vet. Bras. 21:23-32.

Meinkoth J.H., Cowell R.L., Tyler R.D. \& Morton R.J. 2008. Sample collection and preparation, p.1-19. In: Cowel R.L., Tyler R.D., Meinkoth J.H. \& DeNicola D.B. (Eds), Diagnostic Cytology and Hematology of the Dog and Cat. 3rd ed. Mosby Elsevier, Canada. 475p.

Meirelles A.E.W.B., Oliveira E.C., Rodrigues B.A., Costa G.R., Sonne L., Tesser E.S. \& Driemeier D. 2010. Prevalência de neoplasmas cutâneos em cães da Região Metropolitana de Porto Alegre, RS: 1.017 casos (2002-2007). Pesq. Vet. Bras. 30(11):968-973.

Ménard M., Fontaine M. \& Morin M. 1986. Fine needle aspiration biopsy of malignant tumours in dogs and cats: A report of 102 cases. Can. Vet. J. 27:504-510.

Meuten D.J. 2002. Tumors in Domestic Animals. 4th ed. Iowa State Press, Ames, p.509-546.
Mierau G.W., Berry P.J. \& Orsini E.N. 1985. Small Round Cell Neoplasms: can electron microscopy and immunohistochemical studies accurately classify them? Ultrastruct. Pathol. 9:99-111.

Montes O.G.A. 1997. Citologia en la clinica medica de pequeños animales. $2^{\mathrm{a}}$ Jornadas Hospitalarias de Medicina Veterinaria, Buenos Aires, p.111-117.

Motosugi U., Kato T., Kamakura Y., Saze T., Suzuki T., Yajima S., Shimizu Y., Murata S., Shimizu M.J. \& Dobson J. 2001. Small Animal Oncology. Blackwell Science, Oxford.

Nigam J., Misra V., Dhingra V., Jain S., Varma K. \& Singh A. 2013. Comparative study of intra-operative cytology, frozen sections, and histology of tumor and tumor-like lesions of nose and paranasal sinuses. J. Cytol. $30(1): 13-17$.

Ohsie S.J., Sarantopoulos G.P., Cochran A.J. \& Binder S.W. 2008. Immunohistochemical characteristics of melanoma. J. Cutan. Pathol. 35(5):433-444.

Oliveira F.N., Elliott J.W., Lewis B.C., Mathews G.G., Brown R.M., Treadway C.M. \& Langohr I.M. 2012. cutaneous mast cell tumor with epitheliotropism in 3 dogs. Vet. Pathol. 50(2):234-237.

Pakhrin B., Kang M., Bae I., Park M., Jee H., You M., Kim J., Yoon B., Choi Y. \& Kim D. 2007. Retrospective study of canine cutaneous tumors in Korea. J. Vet. Sci. 8:229-236.

Premi S., Wallisch S., Mano C.M., Weiner A.B. \& Bacchiocchi A. 2015. Chemiexcitation of melanin derivatives induces DNA photoproducts long after UV exposure. Science 347(6224):842-847.

Raskin R.E. \& Meyer D.J. 2011. Citologia Clínica de Cães e Gatos: atlas colorido e guia de interpretação. $2^{\underline{a}}$ ed. Elsevier, Rio de Janeiro. 472p.

Rocha N.S. 2008. Exame citológico no diagnóstico de lesões da pele e subcutâneo. Clin. Vet. 76:76-80.

Rodríguez B.J., Ortiz L.C., Garzón A., Gómez L.F. \& Vasquez Y. 2009. Valoración de la citología para el diagnóstico de tumores en caninos. Revta Colomb. Cienc. Pec. 22:42-53.

Rothwell T., Howlett C.D., Middleton D.A., Griffits D.A. \& Duff B.C. 1987. Skin neoplasms of dogs in Sidney. Aust. Vet. J. 64:161-164.

Santos I.F.C., Cardoso J.M.M., Oliveira K.C., Laisse C.J.M. \& Bessa S.A.T. 2013. Prevalência de neoplasias diagnosticadas em cães no Hospital Veterinário da Universidade Eduardo Mondlane, Moçambique. Arq. Bras. Med. Vet. Zootec. 65(3):773-782.

Souza T.M., Fighera F.A., Irigoyen L.F. \& Barros C.S.L. 2006. Estudo retrospectivo de 761 tumores cutâneos em cães. Ciência Rural 36:555560 . 